\title{
Aphthous lesions of the colon as a manifestation
} of metastasized breast cancer
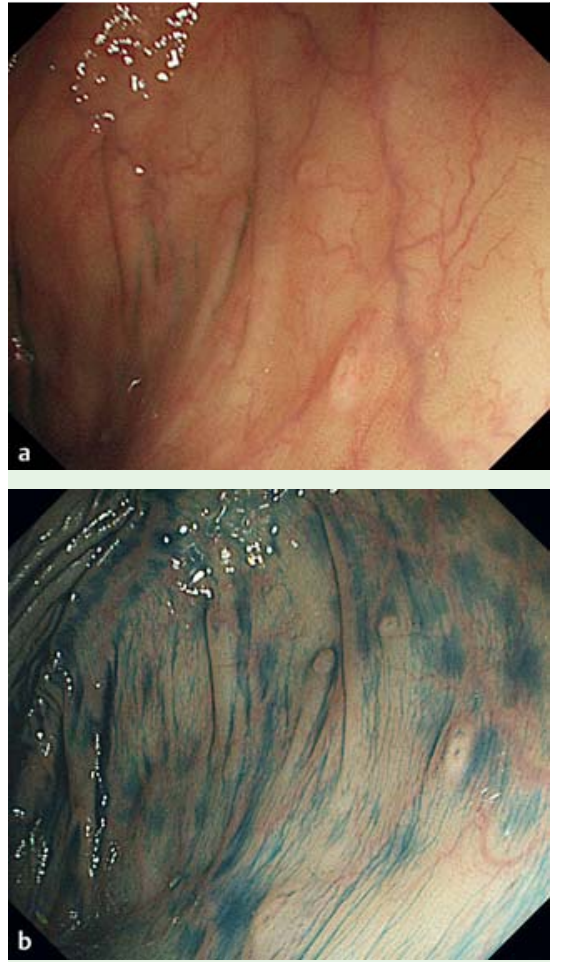

Fig. 1 Colonoscopic image showing multiple whitish aphthous lesions scattered in the transverse colon $(\mathbf{a}, \mathbf{b})$.

A 55-year-old woman underwent right radical mastectomy in 2000 for an invasive ductal carcinoma of the right breast without lymph node metastasis. Although the patient subsequently received adjuvant chemotherapy, she developed a solitary minute gastric metastasis, which was removed by endoscopic resection [1]. She was treated by chemotherapy for the following 6 months. Thereafter, the clinical follow-up showed no signs of tumor recurrence.

At the age of 66 years, the patient underwent screening colonoscopy. On this occasion, multiple whitish aphthous lesions were found in the ascending colon and in the transverse colon ( $\bullet$ Fig. 1).

Histologic examination of the biopsy specimens from the lesions revealed diffuse infiltration of round to oval shaped tumor cells with abundant cytoplasm in the lamina propria ( $\bullet$ Fig. 2a).

Immunohistochemically, the tumor cells were positive for cytokeratin 7 and GCDFP15 ( Fig. 2b), and negative for cytokeratin 20, estrogen receptor, proges-

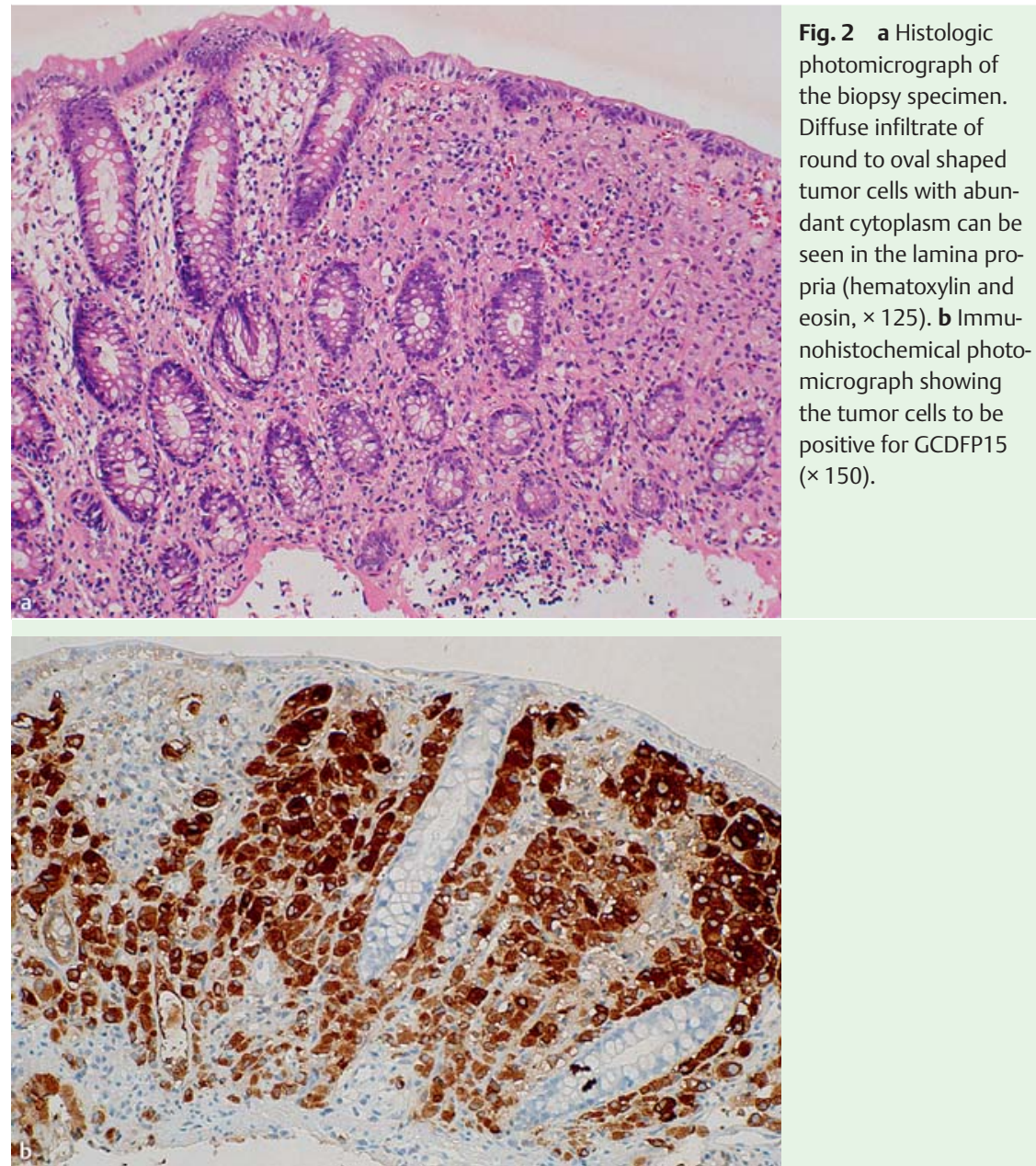

terone receptor, and HER2. Since the staining pattern was similar to that of the patient's primary breast cancer, we diagnosed the colonic lesions as metastatic breast cancer. No other metastatic lesions were confirmed by CT or esophagogastroduodenoscopy. She has been treated by chemotherapy with epirubicin and cyclophosphamide.

Gastrointestinal metastasis from breast cancer is uncommon. On the rare occasions when it happens, the most frequent site has been the stomach. Colonic metastasis has been reported as manifesting in a diffusely infiltrating "scirrhous" pattern [2] or as an eroded protrusion [3]. Although colonic aphthous lesions as seen in our patient have been found in patients with metastatic gastric cancer [4,5], they have not been identified as metastasis of breast cancer.
Our case suggests that colonoscopists should regard diminutive aphthous lesions as a possible sign of colonic metastasis in patients with a previous history of malignant neoplasm.

\section{Endoscopy_UCTN_Code_CCL_1AD_2AB}

\section{Competing interests: None}

\section{A. Hirano ${ }^{1}$, S. Nakamura ${ }^{1}$, K. Fujita ${ }^{2}$, M. Hirahashi ${ }^{2}$, T. Matsumoto ${ }^{1}$}

Department of Medicine and Clinical Science, Graduate School of Medical Sciences, Kyushu University, Fukuoka, Japan

2 Department of Anatomic Pathology, Graduate School of Medical Sciences, Kyushu University, Fukuoka, Japan 


\section{References}

1 Kudo T, Matsumoto T, Nakamura S et al. Solitary minute metastasis from breast cancer mimicking primary intramucosal gastric signet-cell cancer. Gastrointest Endosc 2005; 62: 139-140

2 Taal BG, den Hartog Jager FC, Steinmetz R et $a l$. The spectrum of gastrointestinal metastases of breast carcinoma: II. The colon and rectum. Gastrointest Endosc 1992; 38: $136-141$
3 Feng CL, Chou JW, Huang SF et al. Colonic metastasis from carcinoma of the breast presenting with colonic erosion. Endoscopy 2009; 41: E276-E277

4 Metayer P, Antonietti M, Oumrani $M$ et al. Metastases of a gastric adenocarcinoma presenting as colonic polyposis. Report of a case. Dis Colon Rectum 1991; 34: 622 - 623

5 Hiraga Y, Yasui W, Kumamoto T et al. Colonic metastases of signet-ring cell carcinoma presenting as multiple small depressed lesions like erosions: Report of a case. [in Japanese]. Nippon Shokakibyo Gakkai Zasshi (Jpn J Gastroenterol) 2002; 99: 615-621

\section{Bibliography}

DOI $10.1055 / \mathrm{s}-0030-1256165$

Endoscopy 2011; 43: E131 -E132

(c) Georg Thieme Verlag KG Stuttgart · New York . ISSN 0013-726X

\section{Corresponding author}

\section{A. Hirano, MD}

Department of Medicine and Clinical Science Graduate School of Medical Sciences

Kyushu University, Maidashi 3-1-1, Higashi-ku Fukuoka 812-8582

Japan

Fax: +81-92-642-5273

atsuhira@intmed2.med.kyushu-u.ac.jp 